\title{
A study of asymptomatic bacteriuria in Egyptian school-going children.
}

\author{
Ahmed Mohammed ${ }^{1}$, Magid Abdelfattah ${ }^{1}$, Ayman Ibraheem², Ahmad Younes ${ }^{1}$
}

1. Ain Shams university,Faculty of medicine, Pediatrics

2. Ain Shams university, faculty of medicine, microbiology

\begin{abstract}
Background: Urinary tract infections (UTI) are a common and important clinical problem in childhood. Upper urinary tract infections (i.e., acute pyelonephritis) may lead to renal scarring, hypertension, and end-stage renal disease. Despite the presence of simple and reliable methods of preliminary screening of children's urine, urinary tract infection continues to be under diagnosed.

Objectives: The aim of this study was to establish prevalence rates of significant bacteriuria in asymptomatic school children by simple urine tests in comparison to standard urine culture techniques in Giza, Egypt.

Patients and methods: A total of 1000 apparently healthy school going children (6-12) years, 552 boys (55.2\%) and 448 girls (44.8\%), were enrolled in this cross-sectional prevalence survey.

Results: Overall prevalence of significant bacteriuria was $6 \%$. Higher prevalence occurred in girls (11.4\%) than boys (1.6\%). Escherichia coli was isolated in 35(58\%) cases ( 3 boys and 32 girls), Staph. aureus in $13(22 \%)$ cases (3 boys and 10 girls), Enterobacter in 6 girls (10\%), Kelbsiella pneumoniae in 3 boys (5\%) and Proteus vulgaris in 3 girls (5\%)

Conclusion: Asymptomatic bacteriurea could be detected by urine screening program at school age. Overall prevalence of significant bacteriuria was $6 \%$, with predominance in girls than boys.

Keywords: Bacteriuria, asymptomatic, prevalence, children, school, male, female, simple urine tests.

DOI: http://dx.doi.org/10.4314/ahs.v16i1.9

Cite as: Mohammed A, Abdelfattah M, Ibraheem A, Younes A. A study of asymptomatic bacteriuria in Egyptian school-going children. Afri Health Sci. 2016;16(1): 69-74. http://dx.doi.org/10.4314/abs.v16i1.9
\end{abstract}

\section{Introduction}

Asymptomatic bacteriuria is defined as a significant bacterial count (usually $10^{5}$ organism $/ \mathrm{ml}$ ) present in the urine of a person without symptoms. ${ }^{1}$ Prevalence of asymptomatic bacteriuria differs according to different socioeconomic status and geographical areas. The prevalence of asymptomatic bacteriuria in Egyptian school children was 7\% in a previous study done by El Gamal and Saleh ${ }^{2}$ another study done in India by Kondapaneni et al. revealed a prevalence rate of $16.5 \%^{.3}$

Infection with symptoms will alert a person to take treatment in time to prevent further complications. But in case of asymptomatic persons, they may come to hospital with complications. Early detection of infection in asymptomatic children and prompt therapeutic intervention are essential to prevent cases of asympto-

\section{Corresponding author:}

Ahmed Mohammed,

Ain Shams university,

Faculty of medicine, Pediatrics

Email: ahmedazrak@gmail.com matic UTI from becoming symptomatic with resultant pyelonephritis and renal damage. ${ }^{3}$

A previous study reported that the number of children with bacteriuria was significantly reduced at follow-up six months after antibiotic treatment ${ }^{4}$

Nitrofurantoin and pefloxacin are the most active agents against all bacterial isolates. ${ }^{5}$

There are several rapid tests for the detection of UTI in children. These include leukocyte esterase, nitrate test and catalase test. ${ }^{6}$

For any given test administered to a given population it is important to calculate the sensitivity, specificity, positive predictive value (PPV) and negative predictive value (NPV) in order to determine how useful the test is to detect a disease in a given population. Sensitivity is the probability that an individual with the disease will test positive. ${ }^{7}$ Specificity is the probability that an individual without the disease will test negative ${ }^{7}$. Positive predictive value (PPV) refers to the probability that a positive test correctly identifies an individual who actually has the disease ${ }^{7}$. Negative predictive value (NPV) refers to the probability that a negative test correctly identifies an individual who does not have the disease ${ }^{7}$. 
Urine dipstick testing alone may provide an adequate initial UTI screen ${ }^{8}$ however urine culture is the standard test for the diagnosis of UTI ${ }^{\text {? }}$.

This study aimed to establish prevalence rates of significant bacteriuria in asymptomatic school children by simple urine tests in comparison to standard urine culture techniques in Giza, Egypt.

\section{Patients and methods}

Study design and subjects: This Cross-sectional study was carried out in Giza governorate in Egypt from October 2009 to January 2011. A total of 1000 apparently healthy school going children (6-12) years including 552 males $(55.2 \%)$ and 448 females $(44.8 \%)$ were enrolled in this study. All males had undergone religious based circumcision before enrollment in the study.

They were randomly selected by simple random selection method from 10 primary public schools after obtaining an informed consent from child parents and school managers. The study was approved by the Ethics Committee of the Pediatrics Department, Faculty of Medicine, Ain Shams University.

\section{Randomization steps: (simple random method)}

1- Target population was determined as children attending 10 primary public schools in Giza, Egypt.

2-A frame including list of all children was done.

3- Sample size was determined to be 1000 .

4- Random numbers were developed by specific soft ware used for selection of cases through Spread sheet.

We excluded any child who was feverish or complained from any UTI symptom (dark urine, dysuria, frequency, renal pain, changes of urine volume and suprapubic pain), or received antibiotics during 48 hours prior to sample collection.

The children were clinically examined to exclude any child who had any of the following abnormalities (high temperature, high blood pressure, pallor, jaundice, skin rash, edema and evaluating its extent (puffiness of eye lids), lower limb edema, abdominal tenderness, palpable masses or ascites.

\section{Methods}

All children enrolled in the study were subjected to the following:

Mid stream urine specimens were collected after implementing standard precautions of clean catch urine specimen as follows: For girls, the labia was spread and the perineum cleaned two to three times with antiseptic solution (A cotton sponge soaked with benzalkonium hydrochloride is useful and non-irritating for this purpose. $)^{10}$ or liquid soap and gauze pads. For boys, the meatus was cleansed in a similar fashion. Cleaning the perineum with soap prior to urine collection may decrease the rate of contamination. ${ }^{11}$ The child was instructed verbally to urinate into a toilet or urinal. Midway through urination, a specimen was collected in a sterile container. Midstream urine collection demonstration video was shown to children prior to sample collection. ${ }^{12}$

Each specimen was divided into three parts: the first part of urine was tested with urine dipstick tests for nitrite and leukocyturia, the second part of urine was tested by catalase test, and the third part for culture and sensitivity.

1. Detection of nitrite and leukocyte esterase: a dipstick test (Medi-Test Combi 10®SGL, Macherey Nagel, Germany) was performed on fresh urine specimen with a reagent strip designed to react and progressively produce color changes in 30 seconds. The results were obtained by visual comparison of the test strip with a color chart provided on the bottle label. The test result was considered positive if the dipstick turned pink or red for nitrites or purple for leukocytes within $2 \mathrm{~min}$ utes of contact with the urine.

2. Catalase test: a few drops of $10 \%$ hydrogen peroxide were added to urine tube. A positive test consists of appearance of foam on the surface of urine within two minutes. ${ }^{13}$

3. Urine culture: The remaining part of urine was subjected to microbiologic investigations at the microbiology department, faculty of medicine, Ain shams university (All the urine samples were transported to the laboratory within half an hour to one hour. The distance from laboratory to school is about 20 to 40 minutes. Hence not much time was lost for transportation of samples).

Standard quantitative culture was performed on CLED agar, incubated aerobically at $37^{\circ} \mathrm{C}$ for 24 hours and the developed colonies were counted to detect significant bacteriuria "more than 100,000 organisms/ml"14 and resulting colonies were identified according to standard methods of identification. (After counting of the bacteria colonies, bacteria were identified by taking advantage of the different biochemical properties of bacteria. Bacteria were incubated in different medias with color reactions indicating e.g. enzyme activity (lactase, fermentation, urease), motility or use of citrate as an 
energy source. The results of the biochemical properties were assigned to bacteria species with the help of a table. $)^{15}$

\section{Statistical analysis}

Data was collected; tabulated and Statistical analysis was done by using statistical package for social science (SPSS) version 17 and Microsoft Excel 2007.

Sensitivity is the number of patients with a positive test who have the disease [true positives (TP)] divided by all patients who have the disease [TP/ $(\mathrm{TP}+\mathrm{FN})]$. A test with high sensitivity will not miss many patients who have the disease (i.e., low false negative rate). Whereas $\mathrm{TP}=$ true positives, $\mathrm{FN}=$ false negatives. ${ }^{7,16}$

Sensitivity for Nitrite test: $28 /(28+32)=28 / 60=$ $46.67 \%$

Sensitivity for Catalase test: $19 /(19+41)=19 / 60=$ $31.67 \%$

Sensitivity for Leukocyte esterase: $15 /(15+45)=15 / 60$ $=25 \%$

Sensitivity for Nitrite, Leukocyte esterase and/or Catalase $44 /(44+16)=44 / 60=73.33 \%$

Specificity is the number of patients who have a negative test and do not have the disease (true negatives) divided by the number of patients who do not have the disease [TN/ $(\mathrm{TN}+\mathrm{FP})]$. A test with high specificity will infrequently identify patients as having a disease when they do not (i.e., low false positive results). Whereas $\mathrm{TN}=$ true negatives, $\mathrm{FP}=$ false positives. ${ }^{7,16}$

Specificity for Nitrite test: $872 /(872+68)=872 / 940$ $=92.77 \%$

Specificity for Catalase test: $843 /(843+97)=843 / 940$ $=89.6 \%$

Specificity for Leukocyte esterase: $865 /(865+75)=$ $865 / 940=92 \%$

Specificity for Nitrite, Leukocyte esterase and/or Catalase: $781 /(781+159)=781 / 940=83.08 \%$

Positive predictive value (PPV) is computed from twoby-two tables: true positives / (true positives + false positives) $[\mathrm{TP} /(\mathrm{TP}+\mathrm{FP})]^{7,16}$

Negative predictive value (NPV) is computed from two-by-two tables: true negatives / (false negatives + true negatives) $[\mathrm{TN} /(\mathrm{TN}+\mathrm{FN})] \cdot{ }^{7,16}$

\section{Results}

Nitrite test was positive in $96(9.6 \%)$ urine specimens, leukocyte esterase was positive in $90(9 \%)$ specimens, catalase test was positive in $116(11.6 \%)$ and 203 $(20.3 \%)$ urine specimens were positive for nitrite and $\backslash$ or leukocyte esterase and / or catalase test. (Table 1).

(Table 1): Culture results of urine samples.

\begin{tabular}{|l|l|l|}
\hline & Positive culture $(\mathrm{n}=60)$ & Negative culture $(\mathrm{n}=940)$ \\
\hline Boys (552) & $9(1.6 \%)$ & $543(98.4 \%)$ \\
Girls (448) & $51(11.4 \%)$ & $397(88.6 \%)$ \\
Total (1000) & $60(6 \%)$ & $940(94 \%)$ \\
\hline
\end{tabular}

Sixty out of 1000 urine specimens (i.e., $6 \%$ ) were positive for significant bacteruria by culture with predomi-

nance in girls $(11.4 \%)$ compared to boys $(1.6 \%)$ (Table 2).

(Table 2): Results of different screening tests used.

\begin{tabular}{|l|l|l|}
\hline Tests & Positive & Percentage \\
\hline Nitrite test & 96 & $9.6 \%$ \\
Leukocyte esterase & 90 & $9 \%$ \\
Catalase test & 116 & $11.6 \%$ \\
Nitrite, leukocyte esterase and/or catalase tests & 203 & $20.3 \%$ \\
\hline
\end{tabular}


(Table 3): Types of bacterial isolates in cases of asymptomatic bacteruria.

\begin{tabular}{|l|c|c|c|c|}
\hline Types of bacterial isolates & \multicolumn{2}{|c|}{ Sex } & Total & $\%$ \\
\cline { 2 - 3 } & Boys & Girls & & \\
\hline Escherichia coli (E.coli) & 3 & 32 & 35 & $58 \%$ \\
Staphylococcus aureus & 3 & 10 & 13 & $22 \%$ \\
Enterobacter spp. & - & 6 & 6 & $10 \%$ \\
Klebsiella pneumoniae & 3 & - & 3 & $5 \%$ \\
Proteus vulgaris & - & 3 & 3 & $5 \%$ \\
\hline
\end{tabular}

Out of 96 positive samples by nitrite test, 28 were also positive by culture with sensitivity, specificity, positive predictive value (PPV) and negative predictive value (NPV), 46.67\%, 92.77\%, 29.1\% and $96.5 \%$, respectively. As regards the catalase test, out of 116 positive samples, 19 of them were also positive by culture with sensitivity, specificity, PPV and NPV, 31.67\%, 89\%16.4\% and $95.4 \%$, respectively. Out of 90 leukocyte esterase positive samples only 15 were positive by culture with sensitivity, specificity, PPV and NPV, 25\%, 92\%, 16.7\% and $95 \%$ respectively. While for the combined results of nitrite, leukocyte esterase and/ or catalase out of 203 positive samples 44samples were also positive by culture with sensitivity, specificity, PPV and NPV, 73.33\%, $83.16 \%, 21.7 \%$, and $98 \%$, respectively (Table 4).

(Table 4): Results of screening tests compared to culture.

\begin{tabular}{|c|c|c|c|c|c|c|c|}
\hline \multicolumn{2}{|c|}{ Test } & \multicolumn{2}{|c|}{ Culture } & \multirow{2}{*}{ Sensitivity } & \multirow{2}{*}{ Specificity } & \multirow{2}{*}{ PPV } & \multirow{2}{*}{ NPV } \\
\hline & & (-ve) 940 & $(+v e) 60$ & & & & \\
\hline Nitrate test & $\begin{array}{l}(-v e) 904 \\
(+v e) 96\end{array}$ & $\begin{array}{c}872 \\
68\end{array}$ & $\begin{array}{l}32 \\
28\end{array}$ & $46.67 \%$ & $92.77 \%$ & $29.1 \%$ & $96.5 \%$ \\
\hline Catalase test & $\begin{array}{l}(-v e) 884 \\
(+v e) 116\end{array}$ & $\begin{array}{l}843 \\
97\end{array}$ & $\begin{array}{l}41 \\
19\end{array}$ & $31.67 \%$ & $89 \%$ & $16.4 \%$ & $95.4 \%$ \\
\hline $\begin{array}{l}\text { Leukocyte } \\
\text { esterase }\end{array}$ & $\begin{array}{l}(-v e) 910 \\
(+v e) 90\end{array}$ & $\begin{array}{l}865 \\
75\end{array}$ & $\begin{array}{l}45 \\
15\end{array}$ & $25 \%$ & $92 \%$ & $16.7 \%$ & $95 \%$ \\
\hline $\begin{array}{l}\text { Nitrite, } \\
\text { Leukocyte } \\
\text { esterase and/or } \\
\text { Catalase }\end{array}$ & $\begin{array}{l}(-v e) 797 \\
(+ \text { ve }) 203\end{array}$ & $\begin{array}{l}781 \\
159\end{array}$ & $\begin{array}{l}16 \\
44\end{array}$ & $73.33 \%$ & $83.16 \%$ & $21.7 \%$ & $98 \%$ \\
\hline
\end{tabular}




\section{Discussion}

The prevalence of asymptomatic bacteriuria in schoolgoing children was $6 \%$. Consistent with that obtained by El Gamal and Saleh ${ }^{2}$ Where the prevalence of asymptomatic bacteriuria in Egyptian school children was $7 \%$ and that reported as $7.3 \%$ by Jombo et al. ${ }^{17}$

This was much less than the prevalence detected by Kondapaneni et al. ${ }^{3}$ which was $16.5 \%$ and was also inconsistent with the studies carried by Jalali et al. ${ }^{18}$, Al-Momani, ${ }^{19}$ and Jha and Singh ${ }^{1}$ who reported the prevalence of bacteriuria to be $3.36 \%, 1.39 \%$ and $1.2 \%$, respectively. Such differences may be attributed to different socioeconomic status and geographical areas.

In this study, there is predominance of asymptomatic bacteriuria in girls $11.4 \%$ compared to $1.6 \%$ in boys. This comes in accordance to the studies carried by $\mathrm{Ku}-$ mar et al. ${ }^{20}$ and Jombo et al. ${ }^{17}$ who reported predominance $7.6 \%$ in females to $2.9 \%$ in males and $7.9 \%$ compared to $6.6 \%$ in males, respectively. However, such results disagree with Bakr et al. ${ }^{21}$ who reported that there was no difference according to sex.

E.coli constituted $58 \%$ of the total bacterial isolates consistent with the previously obtained results by Jalali et al. ${ }^{18,15}$, Al-Momani ${ }^{19}$ and Jha and Singh ${ }^{1}$ who reported E.coli isolates to be $50 \%, 57.16 \%$ and $72 \%$ respectively. However, it is more than the results obtained by Kumar et $\mathrm{al}^{21}$ and Kondapaneni, et al. ${ }^{3}$ who reported E.coli isolate to be $32.8 \%$ and $27.27 \%$, respectively.

Noteworthy, E.coli is the most common pathogenscausing UTI. E.coli has different virulence factors like K antigen and capsular polysaccharides which resist immune factors and antibiotics and predisposes to chronic urinary tract infection. ${ }^{22}$

S. aureus constituted $22 \%$ of total bacterial isolates, this comes in accordance to the results obtained by Kondapaneni, et al. ${ }^{3}$ and $\mathrm{El} \mathrm{Gamal}$ and $\mathrm{Saleh}^{2}$ who reported $S$. aureus isolate to be $15 \%$ and $30 \%$ respectively.

The nitrite test was found to have sensitivity of $46.67 \%$ and specificity of $92.77 \%$. The reliability of the nitrite test for urinary tract infections has been investigated widely and it was concluded that false positive results were rare and that the test had a higher specificity for urinary tract infections about $98 \%$ The sensitivity of the test has been reported to be about $50 \% .{ }^{9}{ }^{9,23,24}$

The leukocyte esterase test has sensitivity $25 \%$ and specificity $92 \%$ which is different from previous studies that showed higher sensitivity about $84 \%$ and lower specificity of $78 \% 0^{9,23,24}$
In our study all the screening tests alone or combined showed high negative predictive value of more than 95\%, low positive predictive value (16.4-29.1\%), high specificity (83.16-92.77\%) and lower sensitivity (25$73.33 \%)$.

In a study of 6394 febrile infants aged 1-90 days, Glissmeyer and colleagues found evidence that urine dipstick testing alone may provide an adequate initial UTI screen, comparing well in terms of positive predictive value and specificity with urine microscopy alone or both tests combined. ${ }^{8,25}$ Although the different screens each had a negative predictive value of more than $98 \%$, the dipstick screen had a higher positive predictive value $(66.8 \%)$ than did the combined test $(51.2 \%)$ or microscopy alone $(58.6 \%){ }^{8,25}$ The dipstick test by itself also had a higher specificity $(93.8 \%)$ compared with the combined test $(87.6 \%)$ or microscopy $(91.3 \%)$, although it did have a lower sensitivity than the combined test $(90.8 \% \text { vs. } 94.7 \% \text {, respectively. })^{8,25}$

\section{Limitations}

The studied group were selected from public schools while private schools were not included in the study, we didn't investigate for risk factors of urinary tract infection (for example: anatomical anomalies and vesicoureteral reflux), another limitaion for this study is that we did our best to elaborate to children how to take mid stream urine sample by verbal explanation and video demonstration but we didn't assure this by observing them while collecting the sample.

\section{Conclusion}

Asymptomatic bacteriurea could be detected by urine screening program at school age. Screening for asymptomatic bacteriuria in school-going children helps to know the prevalence. The overall prevalence of significant bacteriuria was $6 \%$, with predominance in girls $(11.4 \%)$ than boys (1.6\%), Escherichia coli was the most common isolated organism in our study (58\%) cases.

\section{Competing interests}

None.

\section{References}

1. Jha BK. and Singh YI. Prevalence of asymptomatic bacteriuria in school going children in Pokhara valley. Kathmandu Univ Med J (KUMJ). 2007; 5:81-4.

2. El-Gamal SA. and Saleh LH. Asymptomatic bacteriuria in school children in a rural area, Egypt. J Egypt Public Health Assoc. 1991; 66 :113-21.

3. Kondapaneni SL, Surpam R, Mohd Azaruddin, Devi 
G. Screening for asymptomatic bacteriuria in schoolgoing children. Indian J Public Health 2012;56:169-70

4. Fitzgerald A, Mori R, Lakhanpaul M. Interventions for covert bacteriuria in children. Cochrane Database Syst Rev. 2012;2:CD006943. doi: 10.1002/14651858. CD006943.pub2.

5. Helen Oroboghae Ogefere and Sunday Ossai Oluka. "Asymptomatic bacteriuria among secondary school students in Benin City, Nigeria. Journal of Public Health and Epidemiology. 2013;2: 66-69.

6. Abu Ghoush, M. W. Screening Test for Detection of Urinary Tract Infections: Evaluation of the Urinary Leukocyte Esterase Dipstick Test. TAF Prev Med Bull 2008.7:187-190 PubMed .

7. Akobeng AK: Understanding diagnostic tests 1: sensitivity, specificity and predictive values. Acta Paediatr. 2007; 96:338-41

8. Glissmeyer EW, Korgenski EK, Wilkes J, Schunk JE, Sheng X, Blaschke AJ, et al. Dipstick screening for urinary tract infection in febrile infants. Pediatrics. 2014; 133:e1121-7.

9. Finnell SM, Carroll AE, Downs SM, Subcommittee on Urinary Tract Infection. Technical report-Diagnosis and management of an initial UTI in febrile infants and young children. Pediatrics. 2011; 128:e749-70.

10. urine analysis: available on website: library.med.utah. edu, accessed on August 11th 2015.

11. Vaillancourt S, McGillivray D, Zhang X, Kramer MS. To clean or not to clean: effect on contamination rates in midstream urine collections in toilet-trained children. Pediatrics. 2007; 119:e1288-e1293.

12. Midstream urine collection practical demonstration( urosurf ): available on web site, e-learning.studmed. unibe.ch, accessed on August 11th 2015.

13. Yehezkel Waisman, Elisheva Zerem, Lisa Amir , Marc Mimouni, The Validity of the Uriscreen Test for Early Detection of Urinary Tract Infection in Children Pediatrics1999;104: 4 pp. e41

14. Kass EH: Asymptomatic infections of the urinary tract. Trans Assoc Am Physicians. 1956; 69:56-64.
15. Urine culture- online textbook of urology available in : www.urology-textbook.com, accessed on August 12th 2015 .

16. How to calculate Sensitivity, Specificity, Positive predictive value, Negative predictive value m.wikihow.com 17. Jombo GTA, Odey F, Ibor S, Bolarin DM , Ejezie GC, Egah DZ, et al. Subclinical significant bacteriuria among pre-school children in calabar municipality: A survey. J.Med.Med.Sci. 2010; 1:134-40.

18. Jalali M, Asteraki T, Emami-MoghadamE, Kalanter E. Epidemiological study of asymptomatic bacteriuria among nursery school children in Ahvaz, Iran. Afr. J. Clin. Exper. Microbiol. 2005; 6:159-61.

19. Al-Momani T. Microbiological study of urinary tract infection in children at Princess Haya Hospital in South of Jordan. Middle East Journal of Family Medicine 2006; 14: 15-8.

20. Kumar CSV, Jairam A, Chetan S, Sudesh P, Kapur I, Srikaramallya. Asymptomatic bacteriuria in school going children. Indian J Med Microbiol.2002; 20:29-32.

21. Bakr A, Sarhan A, Hammad A, Ragab M , Salama OS, Al-Husseni $\mathrm{F}$ et al. Asymptomatic urinary abnormalities among primary school children in Egypt. World J Pediatr. 2007; 3:214-217.

22. Storm DW, Patel AS, Horvath DJ, Li B, Koff SA, Justice SS. Relationship among bacterial virulence, bladder dysfunction, vesicoureteral reflux and patterns of urinary tract infection in children. J Urol 2012;188:23641.

23. Gorelick MH, Shaw KN. Screening tests for urinary tract infection in children: A meta-analysis. Pediatrics 1999;104:e54.

24. Huicho L, Campos-Sanchez M, Alamo C. Meta analysis of urine screening tests for determining the risk of urinary tract infection in children. Pediatr Infect Dis J. 2002;21:1-11.

25. Laidman J. Dipstick test effective initial screen for UTI in Infants. Medscape Medical News . 2014; Accessed December 12, 2014. Available athttp://www. medscape.com/viewarticle/824426. 